\title{
Streamlined extract preparation for Escherichia coli-based cell-free protein synthesis by sonication or bead vortex mixing
}

\author{
Prashanta Shrestha, Troy Michael Holland, and Bradley Charles Bundy \\ Department of Chemical Engineering, Brigham Young University, Provo, UT, USA
}

BioTechniques 53:163-174 (September 2012) doi 10.2144/0000113924

Keywords: sonication; vortex mixing; bead mill; Escherichia coli; extracts preparation; cell-free; cell-free protein synthesis; CFPS; in-vitro protein synthesis

Supplementary material for this article is available at www.BioTechniques.com/article/113924

Escherichia coli-based cell extract is a vital component of inexpensive and high-yielding cell-free protein synthesis reactions. However, effective preparation of $E$. coli cell extract is limited to high-pressure (French press-style or impinge-style) or bead mill homogenizers, which all require a significant capital investment. Here we report the viability of $E$. coli cell extract prepared using equipment that is both common to biotechnology laboratories and able to process small volume samples. Specifically, we assessed the low-capitalcost lysis techniques of: ( $i$ ) sonication, (ii) bead vortex mixing, (iii) freeze-thaw cycling, and (iv) lysozyme incubation to prepare $E$. coli cell extract for cell-free protein synthesis (CFPS). We also used simple shake flask fermentations with a commercially available E. coli strain. In addition, RNA polymerase was overexpressed in the E. coli cells prior to lysis, thus eliminating the need to add independently purified RNA polymerase to the CFPS reaction. As a result, high-yielding $E$. coli-based extract was prepared using equipment requiring a reduced capital investment and common to biotechnology laboratories. To our knowledge, this is the first successful prokaryote-based CFPS reaction to be carried out with extract prepared by sonication or bead vortex mixing.

Cell-free protein synthesis (CFPS) is an in vitro protein transcription/translation system in which cell maintenance and growth is detached from protein synthesis. CFPS enables direct control and optimization of protein synthesis by performing the reaction in a test tube wherein the transcription, translation, and protein folding machinery provided by cell extract are combined with energy sources to catalyze the synthesis of only the target protein. Hence, viable cell extract is a vital constituent of effective cell-free reactions, and cell lysis is a key unit operation in cell extract preparation. Due to the superior control and direct engineering that CFPS affords over protein synthesis, many independent researchers have developed, simplified and optimized CFPS reactions and cell extract preparation procedures (1-10). However, methods for inexpensive and high-yielding Escherichia coli-based CFPS still require specialized cell lysis equipment, resulting in a significant capital investment. In this work, we assess the use of cell lysis techniques with common biotechnology equipment requiring a smaller capital investment to prepare viable $E$. coli-based CFPS extract.

CFPS is an open system devoid of a membrane barrier and is thus amenable to direct engineering. CFPS has been of great use when toxic proteins $(11,12)$, virus-like particles (12-14), membrane proteins (15-17), and proteins containing unnatural amino acids $(18-21)$ are to be produced. Additionally, CFPS compliments other applications including highthroughput functional genomics (22), protein evolution (23-25), and structural proteomics and genomics $(17,26)$. The open nature of the CFPS allows for manifold manipulations of the system, including adjustment of energy, cofactor, and genetic template concentrations, as well as the cell extract itself. For example, many different energy sources such as phosphoenolpyruvate (27), phosphocreatine $(28,29)$, glucose $(30,31)$, and fructose-1,6 bisphosphate (32) have been successfully incorporated into CFPS, and $E$. coli central metabolism and oxidative phosphorylation have been activated $(33,34)$. Additionally, PCR-generated linear DNA templates have been incorporated in CFPS, mitigating the labor- and time-intensive processes of gene cloning $(22,35,36)$. To enable more scientist and engineers to reap the benefits that CFPS has to offer, a simple, robust, convenient, and high-yielding cell extract preparation method is needed.

The E. coli-based system is the least expensive, the highest yielding, and the most time efficient CFPS system (37). The E. coli extract preparation protocol for CFPS dates back to an article from Nirenberg in 1963 (10), which was further modified by Zubay (2) and Pratt (3). More recently, Kigawa et al. 


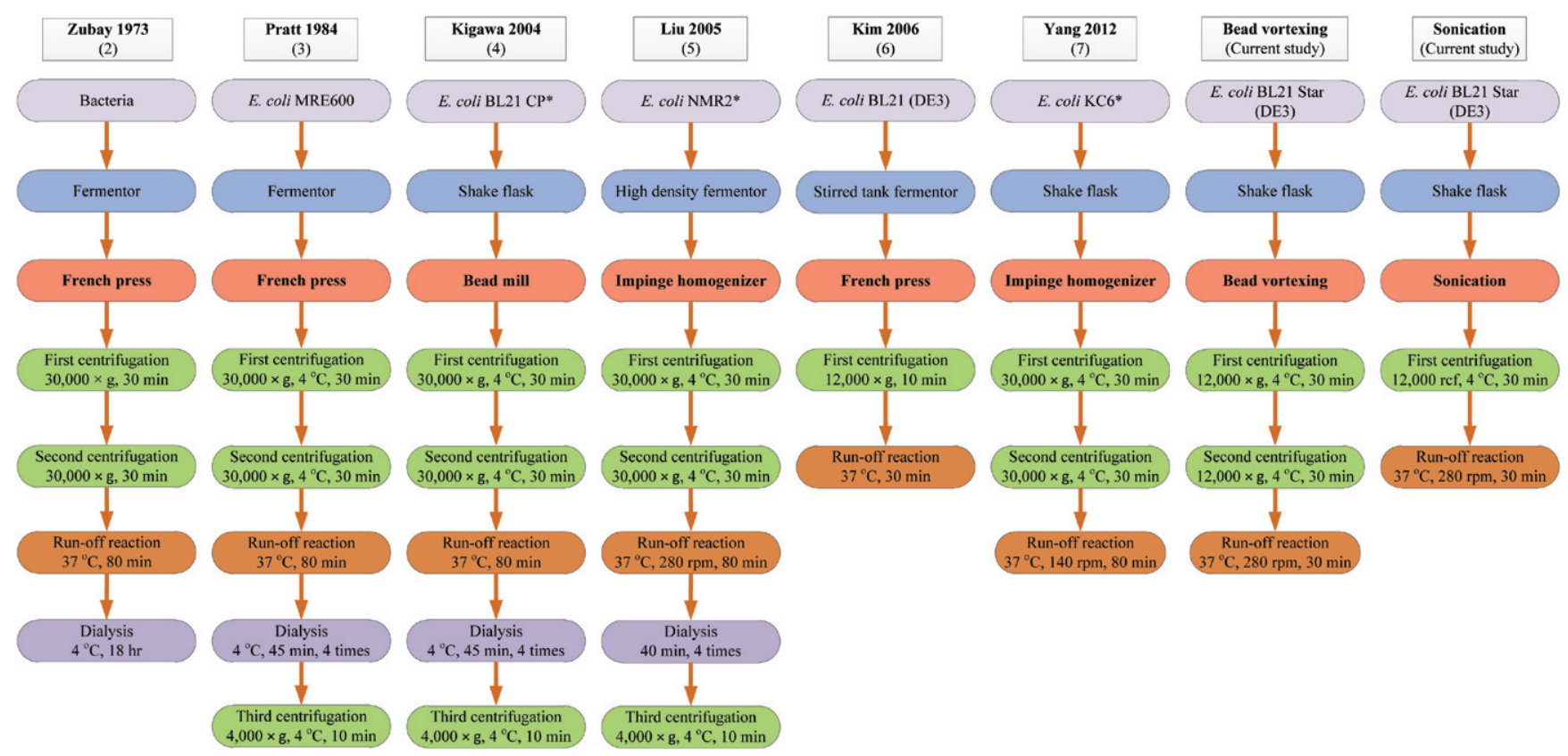

Figure 1. Schematic comparison of different extract preparation methods developed over the last $\mathbf{5 0}$ years. Methods with a star by the cell strain require the addition of independently purified RNA polymerase to the final CFPS reaction. The bead vortex mixing and sonication methods are reported in this paper.

(4), Liu et al. (5), Kim et al. (6), and Yang et al. (7) have sought to streamline the extract preparation protocol. Kim et al. (6) eliminated unnecessary steps and reduced the reagent cost and processing time for extract preparation by up to $80 \%$ when compared with the protocol established by Pratt (3). In addition, Kigawa et al. (4) and Yang et al. (7) have reported the use of shake flask fermentation to simplify the cell growth. Kim et al. (6) also reported the use of the commercial BL21 (DE3) strain (Invitrogen, Carlsbad, CA, USA) to overexpress the T7 RNA polymerase during cell extract preparation and eliminate the need to add independently purified T7 RNA polymerase to the CFPS reaction as required by other protocols $(4,5,7)$. More recently, the same research laboratory reported the use of a BL21 Star (DE3; Invitrogen) strain that contains an RNA stabilizing mutation and will be used in this work (38). Figure 1 provides an overview of these developments. As shown in Figure 1, all of the aforementioned protocols use a specialized bead mill or high-pressure homogenizer (French press-style or impinge-style) for cell disruption, requiring a significant capital investment before research laboratories can assess the efficacy of E. coli-based CFPS for their protein of interest or application. Inspired by the successful use of freeze-thaw cycling for insect-based CFPS (8) and an unsuccessful attempt at using sonication for $E$. coli-based CFPS (4), here we explore more capital-cost-effective cell lysis techniques for $E$. coli-based CFPS. We also will explore streamlining the extract preparation method by combining the simple shake flask fermentation with the use of the commercial BL21 Star (DE3) $E$. coli strain and the highly simplified lysate processing protocol reported by Kim et al. (6).

\section{Materials and methods}

Shake flasks cell culture

Cell growth for extract preparation was performed using BL21 Star (DE3) cells harboring the pEVOL-pPrF plasmid (39) in 2.5-L baffled tunair flasks (IBI Scientific, Peosta, IA, USA). Cells were cultured at $37^{\circ} \mathrm{C}$ with $280 \mathrm{rpm}$ agitation in a rotary incubator shaker (value in $g$ not specified for all incidences of $\mathrm{rpm}$ ). The fermentation was performed with and without the presence of $100 \mathrm{mM}$ 3 -morpholinopropanesulfonic acid (MOPS) in $2 \times$ yeast extract and tryptone (YT) growth media. The fermentations were inoculated with $1 \mathrm{mM}$ isopropyl $\beta$-D-1-thiogalactopyranoside and $0.02 \%$ (w/v) L-arabinose at an optical density $\left(\mathrm{OD}_{600}\right)$ of 0.6. Cells were harvested at mid to late logarithmic growth phase at an $\mathrm{OD}_{600}$ of 2.7 to $3.84 \mathrm{~h}$ after induction by centrifugation at $8000 \mathrm{rpm}$ at $4^{\circ} \mathrm{C}$ for $30 \mathrm{~min}$. Cells were then washed by suspending in $10 \mathrm{~mL}$ ice-cold buffer A $(10 \mathrm{mM}$ Tris base, $14 \mathrm{mM}$ magnesium acetate, $60 \mathrm{mM}$ potassium glutamate, and $1 \mathrm{mM}$ dithiothreitol) per gram of cell and centrifuged at $6000 \mathrm{rpm}$ at $4^{\circ} \mathrm{C}$ for $30 \mathrm{~min}$ and subsequently resuspended in $1 \mathrm{~mL}$ ice-cold buffer A per gram of cell in preparation for cell lysis. Finally, the cell suspension was flash-frozen in liquid nitrogen and stored at $-80^{\circ} \mathrm{C}$ prior to lysis. Note that the pEVOL-pPrF plasmid and its induction with arabinose are not necessary for extract preparation. However, its inclusion in the E. coli cells used for extract preparation enables the option of cell-free production of proteins containing unnatural amino acids.

\section{Cell lysis and extract preparation}

High-pressure homogenization. Thawed cell suspensions were lysed with three passes through an Emulsiflex-B15 French press-style high-pressure homogenizer (Avestin, Ottawa, ON, Canada) at 24,000 psi with sample cooling for $1 \mathrm{~min}$ in an ice-water bath after the second pass. The lysate was centrifuged at $12,000 \times \mathrm{g}$ for $10 \mathrm{~min}$ at $4^{\circ} \mathrm{C}$, and the pellet was discarded. The supernatant was carried forward for a run-off 


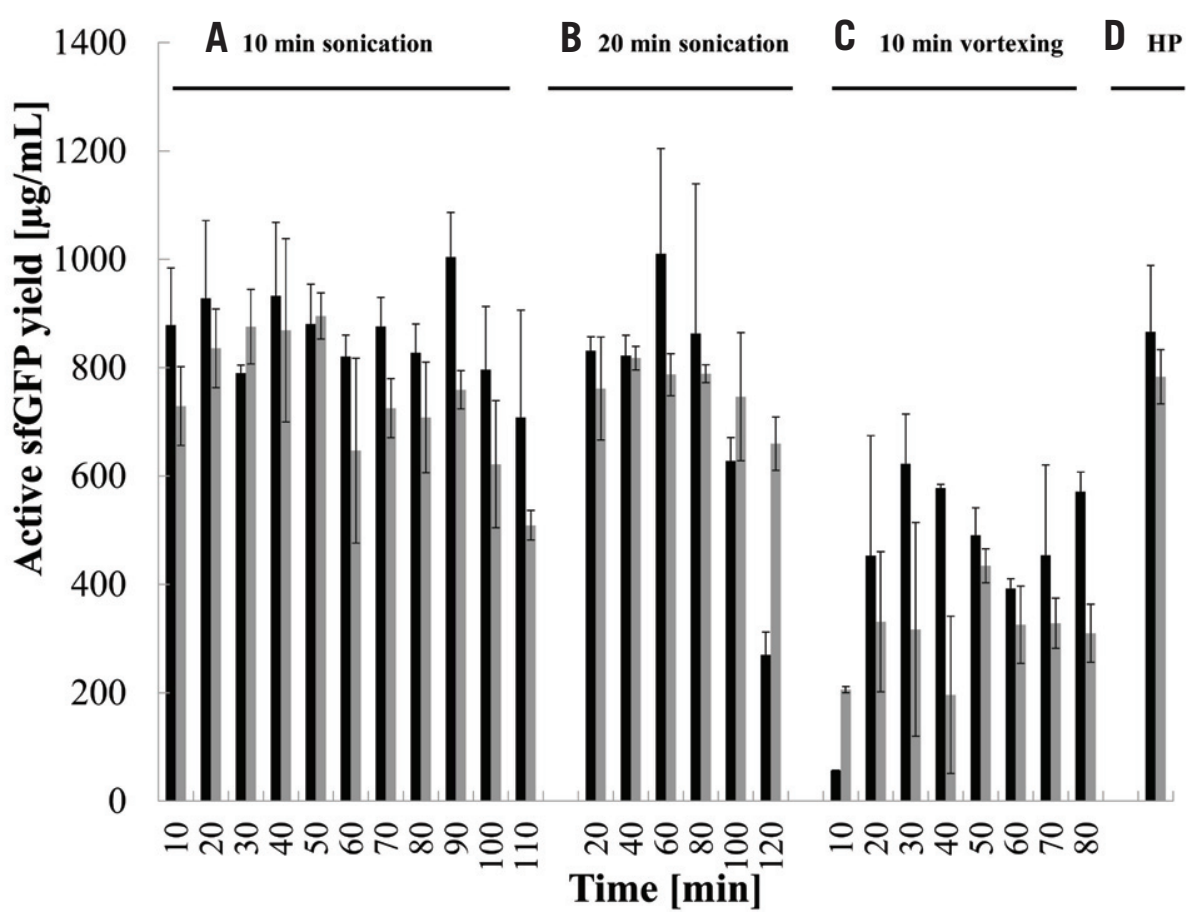

Figure 2. Protein production with extracts prepared from cells lysed with sonication, bead vortex mixing, and high-pressure homogenization. Protein production yields from extracts prepared by lysing cells with 10 -min sonication burst with 2 -min $4^{\circ} \mathrm{C}$ cooling cycles (A), 20-min sonication burst with 2 -min $4^{\circ} \mathrm{C}$ cooling cycles (B), 10-min bead vortex mixing with 1-min $4^{\circ} \mathrm{C}$ cooling cycles (C), and French press-style high-pressure homogenization (D), represented as $\mathrm{HP}$ in the figure. The dark and light bars represent the protein yields from CFPS reactions using extracts prepared from cells grown in fermentations with and without MOPS, respectively. Error bars represent the standard deviation from triplicate CFPS reactions. The x-axis represents the total amount of sonication time or bead vortex mixing time applied to the cells for lysis and excludes the time spent cooling. Each time point effectively represents an additional lysis and cooling cycle.

reaction by incubating at $37^{\circ} \mathrm{C}$ with 280 rpm agitation for $30 \mathrm{~min}$. The extract was flash-frozen in liquid nitrogen and stored at $-80^{\circ} \mathrm{C}$ until use.

Sonication. Thawed cell suspensions were lysed using a Vibra-cell VCX 400 probe sonicator with a CV 26 probe (tip diameter of $3 \mathrm{~mm}$; Sonics \& Materials, Newtown, CT, USA) at a frequency of $20 \mathrm{kHz}$. The sample vial was kept in an ice-water bath to prevent significant heating in the sample during sonication. The lysate was centrifuged for $30 \mathrm{~min}$ at $12,000 \times g$ at $4^{\circ} \mathrm{C}$, and the run-off reaction was performed by incubating the supernatant at $37^{\circ} \mathrm{C}$ with $280 \mathrm{rpm}$ agitation for $30 \mathrm{~min}$. The extract was flash-frozen in liquid nitrogen and stored at $-80^{\circ} \mathrm{C}$ until use. Sonication was performed by cycling at the sonication and cooling intervals as shown in Table 1.

Bead vortex mixing. Glass beads of $0.1 \mathrm{~mm}$ diameter (Scientific Industries, Bohemia, NY, USA) at 10\%, 20\%, 50\% or $80 \%(\mathrm{w} / \mathrm{v})$ beads-to-cell suspension ratio were used for cell lysis in 1.5 - or 2 -mL microcentrifuge tubes. The cell and bead suspension was vortex mixed on the table top vortex mixer, Fisher Vortex Genie 2 (Scientific Industries), at 3200 rpm for different time intervals with a 1-min cooling period between each vortex mixing. The lysate was centrifuged twice at $12,000 \times g$ at $4^{\circ} \mathrm{C}$ for $30 \mathrm{~min}$ with the supernatant retained each time. The run-off reaction was performed at $37^{\circ} \mathrm{C}$ and $280 \mathrm{rpm}$ shaking for $30 \mathrm{~min}$. The extract was flash-frozen in liquid nitrogen and stored at $-80^{\circ} \mathrm{C}$ until use.

Lysozyme incubation. Hen egg white lysozyme (Sigma-Aldrich, St. Louis, MO, USA) was added to the thawed cell suspension at a concentration of $0.1 \mathrm{mg} / \mathrm{mL}$ and incubated at $37^{\circ} \mathrm{C}$ with gentle shaking $(80 \mathrm{rpm})$ for 3 $\mathrm{h}$, similar to as reported previously (40). The lysate was centrifuged at $12,000 \times g$ at $4^{\circ} \mathrm{C}$ for $10 \mathrm{~min}$. The run-off reaction was performed by incubating the supernatant at $37^{\circ} \mathrm{C}$ and $280 \mathrm{rpm}$ shaking for $30 \mathrm{~min}$. The extract was flash-frozen in liquid nitrogen and stored at $-80^{\circ} \mathrm{C}$ until use.

Freeze-thaw cycling. Thawed cell suspensions of $500 \mu \mathrm{L}$ in $1.5-\mathrm{mL}$ microcentrifuge tubes were subjected to three freeze-thaw cycles by freezing the cell suspensions on liquid nitrogen or dry ice for $15 \mathrm{~min}$ and thawing for $15 \mathrm{~min}$ in a water bath at $25^{\circ} \mathrm{C}$, similar to previously reported methods $(41,42)$. The lysate was centrifuged at $12,000 \times g$ at $4^{\circ} \mathrm{C}$ for $10 \mathrm{~min}$. The run-off reaction was performed by incubating the supernatant at $37^{\circ} \mathrm{C}$ and $280 \mathrm{rpm}$ shaking for $30 \mathrm{~min}$. The extract was flash-frozen in liquid nitrogen and stored at $-80^{\circ} \mathrm{C}$ until use.

Cell-lysis efficiency determination The concentration of the $E$. coli cells used for extract preparation was determined using the wet-weight as measured following cell harvest (1 trillion E. coli cells per gram wet weight). Following lysis and before clarification by centrifugation, the lysate was diluted 50, 2500, 120,000 , and 24,000,000 fold. Twenty microliters from the dilutions were plated on sterile Luria-Bertani agar Petri dishes (without antibiotics) and incubated overnight at $37^{\circ} \mathrm{C}$. The lysis efficiency was determined by comparing the numbers of colonies on each plate to the total number of cells that would be present in the corresponding same volume and dilution if the cells were not lysed.

Cell-free protein synthesis reaction PANOx-SP energized cell-free reactions were performed on a flat bottomed 96-well black microtiter plate (Fisher 


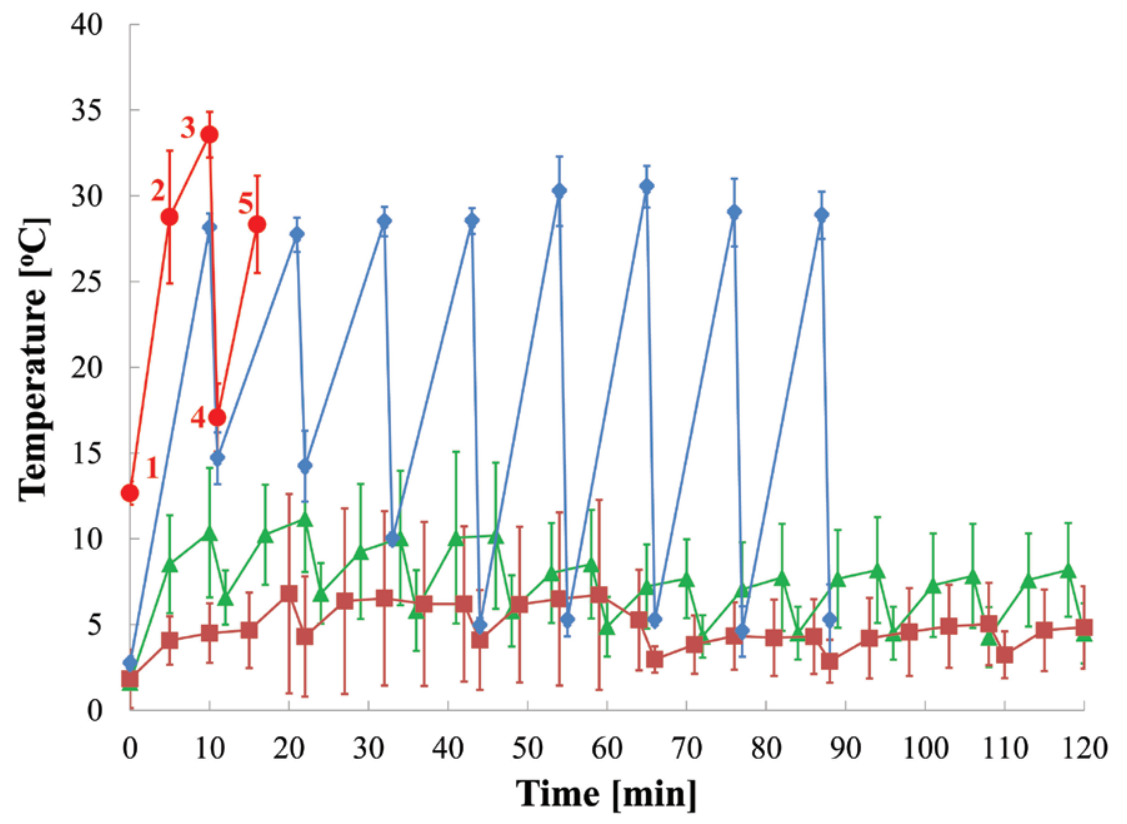

Figure 3. Temperature of sample during sonication and bead vortex mixing. Blue diamonds represent 10 min continuous bead vortex mixing with 1 min cooling in an ice-water bath. Green triangles and red squares represent continuous sonication for $10 \mathrm{~min}$ and 20 min with 2 min cooling time in between each burst. Sonication and cooling were performed in an ice-water bath. Red dots represent the temperature of the sample at different stages during French press-style high-pressure homogenization with the order of pass above or beside the dot. Legend for high-pressure homogenization: 1, temperature of the sample at the beginning; 2, temperature of the lysate after the first pass; 3 , temperature of the sample after the second pass; 4 , temperature of the sample after cooling for a 1-min ice-water bath in a steel beaker; and 5, temperature of the lysate after the third pass. The error bar with the corresponding colors represents the standard deviation of triplicate temperature measurements.

Scientific, Waltham, MA, USA) with reaction volume of $15 \mu \mathrm{L}$ at $37^{\circ} \mathrm{C}$ for 3 $\mathrm{h}$ with the following modifications: $(i)$ radiolabeled leucine was not added to the reaction mixture, $(i i)$ cell extract was used at $24 \%-25 \%(\mathrm{w} / \mathrm{v})$ concentration, and (iii) BL21 Star DE3 E. coli cell strain was used for extract preparation, eliminating the need for addition of purified T7 RNA polymerase (13). Phosphoenolpyruvate and $E$. coli tRNA mixture were obtained from Roche Molecular Biochemicals (Indianapolis, IN, USA). All other reagents were obtained from Sigma-Aldrich. The super-folder green fluorescent protein (sfGFP) expression plasmid used in this work has been reported previously (18). The protein yield was determined by diluting the reaction volume to $60 \mu \mathrm{L}$ with MilliQ water (Millipore, Billerica, MA, USA) in flat-bottomed 96-well black microtiter plates and measuring the fluorescence with a SYNERGY MX microplate reader (BioTek Instruments, Winooski, VT, USA) at a sensitivity setting of 50 and excitation/emission wavelengths of 485 and $510 \mathrm{~nm}$, respectively. A calibration curve was used to determine
"We found speed, quality, resolution and versatility in the Fragment Analyzer."

Dr. Sunil Chandran Senior Scientist, Amyris, Inc.
Fragment Analyzer ${ }^{\mathrm{TM}}$ customers since its January, 2012 introduction:

Dozens of core labs regularly use the Fragment Analyzer to qualify DNA fragments prior to NGS runs

20 government institutes and labs in Germany, France, Austria, Switzerland, the United Kingdom, Italy, South Korea, Japan, China, Brazil, Canada and the U.S.

I8 leading U.S. plant science universities

I3 medical genetic/genomics testing firms

7 U.S. medical schools

6 of the 10 biggest seed companies in the world

3 Ivy League schools

- Biofuels manufacturers

Children's hospitals

Pharmaceuticals manufacturers

Medical research foundations

\section{Results and discussion}

Shake flask cell culture

The use of shake flask fermentation and a common commercial E. coli strain, BL21 Star (DE3) for extract preparation simplifies the fermentation and eliminates the need to add independently purified RNA polymerase to the reaction or the acquisition of a specialized cell strain. While effective at producing E. coli cells viable for producing CFPS extract (7), the nutrient concentrations and $\mathrm{pH}$ are not directly controlled during shake flask fermentation. To assess the effect of the $\mathrm{pH}$ change during fermentation on extract viability, $E$. coli cells were fermented with and without the presence of $100 \mathrm{mM}$ MOPS. Although, over the course of the fermentation, the $\mathrm{pH}$ exhibited a smaller change with MOPS (Supplementary Figure S1), the average sfGFP production yields from the extract prepared from cells grown in MOPS was within a standard deviation of the extract prepared from cells grown
Reverse genetics TILLiNG sites, including the world's largest corporate provider of TILLiNG services

- International universities in Germany, France, Switzerland, Japan, Brazil, Canada and the United Kingdom

Each day dozens of labs use the Fragment Analyzer to separate genomic DNA fragments as large as 40,000 base pairs

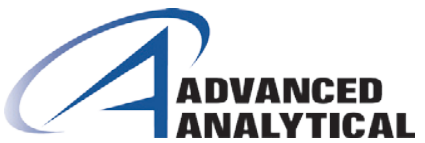

www.aati-us.com

"The Fragment Analyzer is easy to use and performs many tasks."

Dr. Caroline Allix-Béguec R\&D Manager, Genoscreen 
Table 1. Sonication time and cooling time intervals in between for extract preparation using sonication.

\begin{tabular}{|c|c|c|c|}
\hline $10 \mathrm{~s}$ & $30 \mathrm{~s}$ & $587 \pm 178$ & High \\
\hline $20 \mathrm{~s}$ & $60 \mathrm{~s}$ & $588 \pm 66$ & High \\
\hline $60 \mathrm{~s}$ & $90 \mathrm{~s}$ & $731 \pm 66$ & High \\
\hline $10 \mathrm{~min}$ & $2 \min$ & $1004 \pm 82^{a}$ & Low $^{a}$ \\
\hline $20 \mathrm{~min}$ & $2 \min$ & $1010 \pm 194^{a}$ & Low $^{a}$ \\
\hline
\end{tabular}

aData obtained beyond 100 min of total sonication time was not included in the analysis. sfGFP yield results shown in Figure 3 for 10 min and 20 min burst times, with all other burst time data shown in Supplementary Figure S3.

Yield represents the highest obtained active sfGFP yield with corresponding standard deviation $(n=3)$. High variability is defined as variation of greater than $25 \%$ in protein production yields when identical conditions for preparing the CFPS extract were repeated. Low variability is defined as variation less than $25 \%$ in protein production yields when identical conditions for preparing the CFPS extract were repeated.

without MOPS (see Figure 2D). Thus the inclusion of MOPS in the fermentation did not significantly affect extract performance.

Performance of extract prepared with sonication

The purpose of using sonication cell lysis as opposed to the previously reported lysis by bead mill and high-pressure homogenizers is to reduce the capital cost and enable researchers without access to these specialized equipment the opportunity to assess and use CFPS for their desired application. The capital cost of the bead mill or high-pressure homogenizers used in this work and reported by others to produce CPFS extract is approximately $\$ 10,000$ to $\$ 40,000$ (Supplementary Table S1) compared with the commonly available sonicator, which costs about $\$ 4000$ (Supplementary Table S1).

For cell lysis, the sonication burst periods and $4^{\circ} \mathrm{C}$ cooling periods were initially selected based upon commonly reported protocols for cell lysis, which use 10 - to 60 -s sonication burst periods and $3-10$ cycles as shown in Table $1(43-46)$. However, following these sonication protocols for cell lysis, the resulting CFPS extract produced protein at yields $<25 \%$ of that achieved using a high-pressure homogenizer (Supplementary Figure S3). Also, different from the simplified Kim et al. (6) protocol using a French pressstyle high-pressure homogenizer (Figure 1), centrifugation for $30 \mathrm{~min}$ was needed to clarify the extract to appear similar to that obtained by high-pressure homogenization and $10 \mathrm{~min}$ of centrifugation.
Although the sonication-produced extract was less productive than that produced by high-pressure homogenization, continued sonication burst-cooling cycles, and thus longer total sonication times, did in most cases result in a more productive CFPS extract (Supplementary Figure S3). However, a significant limitation was the variation in extract productivity observed among replicates (Table 1 and Supplementary Figure S3). This result was not surprising given that Kigawa et al. (4) claimed from their tests that sonication was not suitable for $E$. coli-based CFPS extract preparation. Although Kigawa et al. did not report the method used or the actual data from testing sonication; it is likely they also used common sonication protocols for $E$. coli cell lysis.

Based upon the trend of higher yields from both longer sonication burst periods and longer total sonication time (Table 1 and Supplementary Figure S3), we increased the sonication burst period to 10 or $20 \mathrm{~min}$ with a $2-\mathrm{min} 4^{\circ} \mathrm{C}$ cooling period. For a direct comparison to the traditional extract preparation protocol with a high-pressure homogenizer, cell aliquots from the same shake flask fermentations (with and without MOPS) reported in Supplementary Figure S1 were used with sonication. The protein production yields obtained with CFPS extracts prepared using the 10 - or 20 -min sonication burst and a 2 -min cooling period are shown in Figure 2, A and B. Similar results were obtained from cells harvested from either fermentation (with or without MOPS). The extracts prepared by sonication were also suitable for CFPS using linear DNA templates (see Supplementary Figure S5). Also, continuing the sonication burst-cooling cycle beyond the first sonication burst-cooling cycle was not necessary to obtain a CFPS extract as productive as that obtained from highpressure homogenization (Figure 2, A, B, and D). In addition, the CFPS extract productivity remained fairly constant over $100 \mathrm{~min}$ total sonication time $(10$ cycles for the 10 -min sonication burst, and 5 cycles for the 20-min sonication burst) (Figure 2, A and B).

One concern of lysis by sonication is sample heating, and Kigawa et al. (4) postulated that sample heating is a possible reason why in their tests sonication was not suitable for preparing CFPS extract. The temperature of cell samples was measured over $120 \mathrm{~min}$ with continuous cycling between the 10 - or 20-min sonication burst and 2 min cooling. The temperature of three independent experiments was measured by a K-type mini thermocouple, and the average remained below $15^{\circ} \mathrm{C}$ throughout the 120 -min run (Figure 3, triangle and square data). In comparison, the average temperature of the cell samples processed by high-pressure homogenization was much higher with the maximum approaching $34^{\circ} \mathrm{C}$. Also, sonicated CFPS extract productivity did not significantly decrease over $100 \mathrm{~min}$ of sonication, suggesting the extract was not damaged by heat.

The efficiency of lysis by sonication was also assessed relative to a French press-style high-pressure homogenizer by plating dilutions of lysate on LB broth agar Petri dishes. Lysis efficiency 
increased with total sonication time, with 10 cycles of $10 \mathrm{~s}$ sonication resulting in $98.898 \%$ lysis, 40 cycles of 10 s sonication resulting in $99.789 \%$ lysis, and $10 \mathrm{~min}$ of continuous sonication resulting in 99.988\% lysis. The high-pressure homogenizer had the highest efficiency at 99.9996\%. By comparing lysis efficiency alone, it appears that very high lysis efficiency $(>99.98 \%)$ is needed for the consistent preparation of productive $E$. coli extract for CPFS. Although, other factors also play a role, such as the formation of soluble inverted membrane vesicles to facilitate oxidative phosphorylation CFPS, as reported with extracts prepared using a high-pressure homogenizer $(34,47)$.

Performance of cell extract prepared using bead vortex mixing

With simplifying the extract preparation as our ultimate goal, we also sought to simplify the bead milling process for extract preparation by using a table top vortex mixer with $0.1-\mathrm{mm}$ diameter glass beads. This method is significantly more economical than the commercial bead mill method (approximately \$10,000$\$ 40,000$ for a commercial bead mill; Supplementary Table S1) compared with about $\$ 350$ for the commonly available table top vortex mixer (Supplementary Table S1). Commercial bead milling equipment has been regularly used for protein purification $(48,49)$, DNA extraction (50), cell-free extract preparation $(4,51)$, and lipid extraction (52).

Initial attempts with bead vortex mixing were performed with $10 \%$, $20 \%, 50 \%$, and $80 \%(\mathrm{w} / \mathrm{v})$ bead. Of the different combinations, only the bead concentration recommended by the manufacturer $[80 \%(\mathrm{w} / \mathrm{v})$ bead-tocell buffer ratio] produced a significant amount of protein (results not shown) and was therefore chosen for further experiments. Also, cell lysates obtained by bead vortex mixing were observed to have a higher viscosity, and two centrifugation steps of $30 \mathrm{~min}$ each were required to adequately clarify the lysate. The protein yield obtained with extract prepared by cycling between bead vortex mixing and cooling in ice water resulted in lower protein production yields and higher extract-to-extract variability (Figure 2C and Supplementary Figure S4) as compared with protein production yields from extracts prepared by highpressure homogenization and $10+\mathrm{min}$ of sonication. Lysis efficiency following two and five cycles of 10 -min bead vortex mixing was $99.378 \%$ and $99.479 \%$, respec- tively, which is lower than that observed with the high-pressure homogenization and $10 \mathrm{~min}$ of sonication. The bead vortex mixing lysis efficiency observed is similar to that observed at lower sonication times, which also resulted in CFPS extract with lower protein yields and higher variability between replicate extract preparations. Increasing the vortex mixing time beyond $80 \mathrm{~min}$ seemed unreasonable for a streamlined extract preparation method. Also of note is the large temperature swings observed by cycling between bead vortex mixing and cooling, although temperatures higher than that obtained with the highpressure homogenizer were not observed (Figure 3). Although there are challenges associated with this method, yields up to $600 \mu \mathrm{g} / \mathrm{mL}$ sfGFP production were obtained from CFPS extract prepared with bead vortex mixing.

Performance of cell

extract prepared by

freeze-thaw and lysozyme

As part of this work, the simple cell lysis methods of freeze-thaw and enzymatic lysis by lysozyme were also assessed for preparing CFPS extract. However, the extracts prepared using these techniques did not produce measurable amounts of protein in CFPS reactions (results not shown). Lysis efficiencies of $99.609 \%$ to 99.976\% for freeze-thaw and 99.991\% for lysozyme were observed. These efficiencies are comparable to the lysis efficiency obtained after $10 \mathrm{~min}$ of sonication (99.988\%), suggesting insufficient lysis was not the reason for the unviable extract. In contrast to lysis by a high-pressure homogenization or sonication, the freeze-thaw and lysozyme lysis methods do not involve mechanical shearing, which may be important for viable $E$. coli cell extract $(40,53)$. However, freeze-thaw lysis has been reported as a viable method to produce insect cell extract for CFPS (8), which suggests that with further engineering such a method could be developed for $E$. coli cell extract preparation.

In this work, we have sought to simplify the cell extract preparation method using equipment common to biotechnology laboratories, thus eliminating the need for specialized growth and lysis equipment. This was accomplished by performing cell growth in shake flasks and assessing the alternative $E$. coli disruption techniques of: (i) sonication, (ii) bead vortex mixing, (iii) enzymatic lysis, and (iv) freeze-thaw cycling. Using sonication, we were able

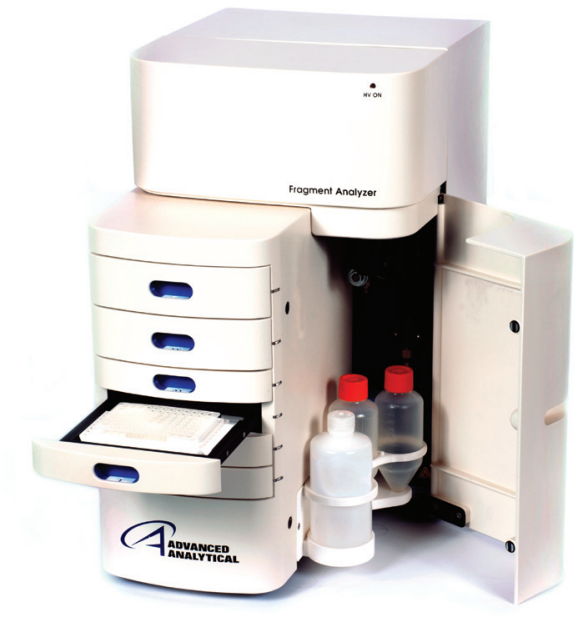

\section{Fragment Analyzer ${ }^{T M}$ applications:}

Q Qualifying fragments for NGS work

- RNA analysis

- Genotyping

- Genomic DNA to 40,000 bp

Reverse genetics mutation detection

Population mapping

Biomarker development

12 or 96 sample format

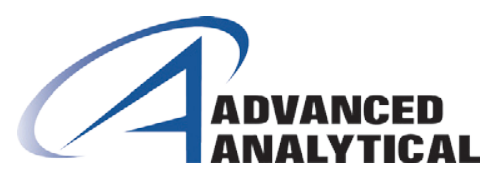

\section{Contact us today}

to learn about our

multiple instrument

purchase discount. 
to reproducibly produce high-yielding CFPS extract and, in terms of capital equipment cost, sonication is approximately $60 \%$ to $90 \%$ less expensive than the developed techniques shown in Figure 1. Also, sonication is well suited for laboratories with access to a sonicator but not a bead mill or a highpressure homogenizer. Another benefit of sonication is that sample volumes as low as $150 \mu \mathrm{L}$ can be processed, and 96-well plate sonicators are available for high-throughput applications (Supplementary Table S1). Extracts produced by sonication could also be engineered for other cell-free configurations, such as continuous exchange CFPS, which enables extended reaction durations and higher productivities. For researchers without access to a sonicator, bead

\section{BD PureCoat $^{\mathrm{TM}}$ ECM Mimetic Cultureware}

Chemically-synthesized, animal-free pre-coated cultureware

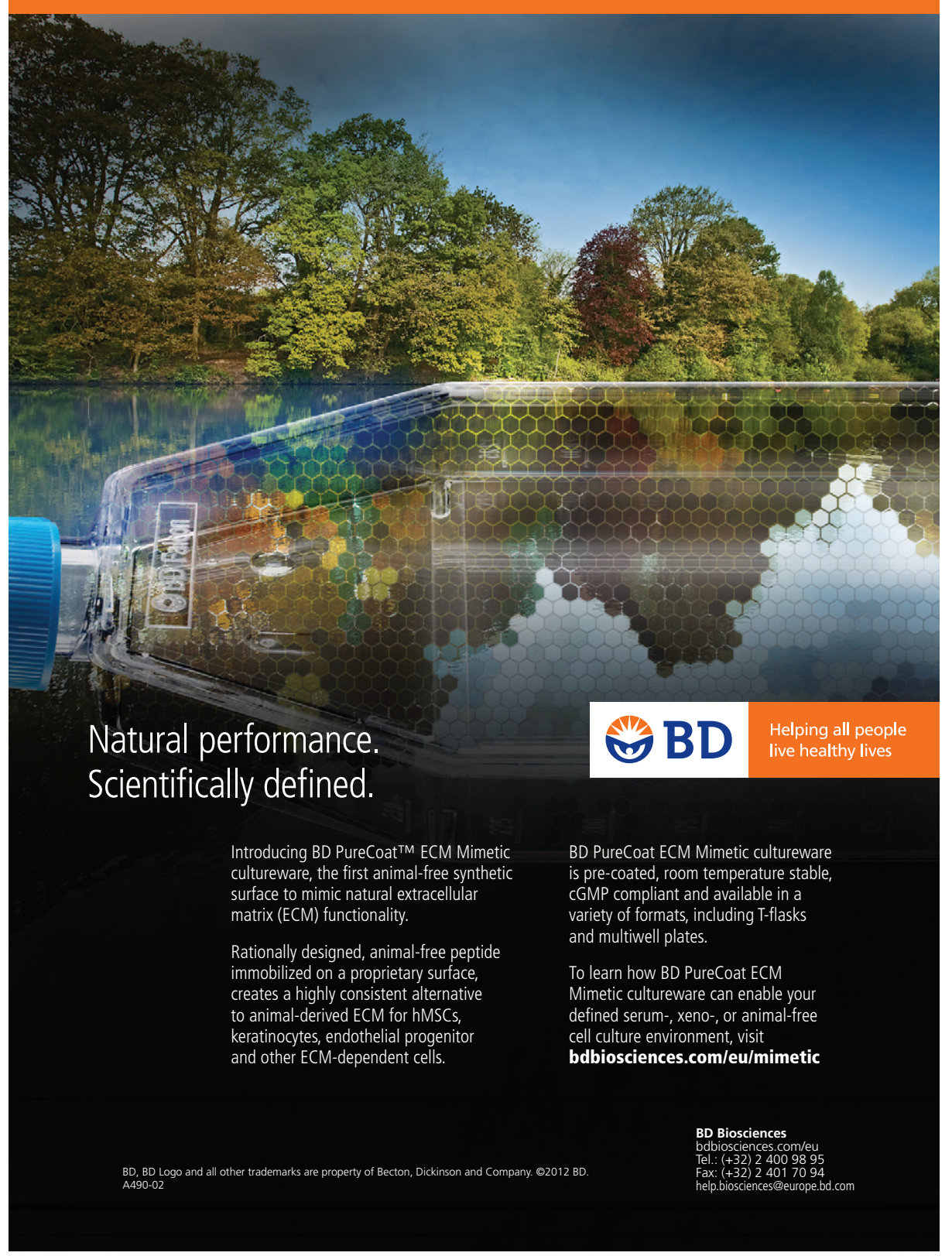

vortex mixing can also be used for extract preparation, although the CFPS yields obtained through this lysis method are lower than those obtained using sonication or high-pressure homogenization with higher extract-to-extract variability. In conclusion, the combination of shake flask cell culture, sonication or bead vortex mixing cell lysis technique, and streamlined extract preparation protocol described in this work can significantly reduce the time, effort, and capital cost expended in initial proof-of-concept experiments with CFPS. We believe this simple extract preparation technique could become an economically sound milestone for extract preparation and will enable more scientists and engineers to test CFPS for their desired application.

\section{Acknowledgments}

We would like to thank Dr. William G. Pitt (Brigham Young University, UT, USA) for use of his sonicator and Dr. Peter G. Schultz (Scripps Research Institute, CA, USA) for generous gift of pEVOL- $p$ PrF plasmid harbored in the BL21 Star (DE3) strain used in this work. This work was supported by a Brigham Young University Mentoring Environment Grant and the National Science Foundation grant no. 1115229.

\section{Competing interests}

The authors declare no competing interests.

\section{References}

1. Bretthauer, R.K., L. Marcus, J. Chaloupka, H.O. Halvorson, and R.M. Bock. 1963. Amino acid incorporation into protein by cell-free extracts of yeast. Biochemistry 2:1079-1084.

2. Zubay, G. 1973. In vitro synthesis of protein in microbial systems. Annu. Rev. Genet. 7:267-287.

3. Pratt, J.M. 1984. Coupled transcriptiontranslation in prokarytoic cell-free systems, p. 179-209. In B.D. Hames, S.J. Higgins (Eds.), Transcription and Translation: A Practical Approach. IRL Press, New York.

4. Kigawa, T., T. Yabuki, N. Matsuda, T. Matsuda, R. Nakajima, A. Tanaka, and S. Yokoyama. 2004. Preparation of Escherichia coli cell extract for highly productive cell-free protein expression. J. Struct. Funct. Genomics 5:63-68.

5. Liu, D.V., J.F. Zawada, and J.R. Swartz. 2005. Streamlining Escherichia coli S30 extract preparation for economical cell-free protein synthesis. Biotechnol. Prog. 21:460-465.

6. Kim, T.W., J.W. Keum, I.S. Oh, C.Y. Choi, C.G. Park, and D.M. Kim. 2006. Simple procedures for the construction of a robust 
and cost-effective cell-free protein synthesis system. J. Biotechnol. 126:554-561.

7. Yang, W.C., K.G. Patel, H.E. Wong, and J.R. Swartz. 2012. Simplifying and streamlining Escherichia coli-based cell-free protein synthesis. Biotechnol. Prog. 28:413-420.

8. Ezure, T., T. Suzuki, S. Higashide, E. Shintani, K. Endo, S. Kobayashi, M. Shikata, M. Ito, et al. 2006. Cell-free protein synthesis system prepared from insect cells by freeze-thawing. Biotechnol. Prog. 22:1570-1577.

9. Takai, K., T. Sawasaki, and Y. Endo. 2010. Practical cell-free protein synthesis system using purified wheat embryos. Nat. Protocols 5:227238.

10. Nirenberg, M.W. 1963. Cell-free protein synthesis directed by messenger RNA. Methods Enzymol. 6:17-23.

11. Avenaud, P., M. Castroviejo, S. Claret, J. Rosenbaum, F. Megraud, and A. Menard. 2004. Expression and activity of the cytolethal distending toxin of Helicobacter hepaticus. Biochem. Biophys. Res. Commun. 318:739-745.

12. Smith, M.T., C.T. Varner, D.B. Bush, and B.C. Bundy. 2012. The incorporation of the A2 protein to produce novel Qbeta virus-like particles using cell-free protein synthesis. Biotechnol. Prog. 28:549555.

13. Bundy, B.C., M.J. Franciszkowicz, and J.R. Swartz. 2008. Escherichia coli-based cell-free synthesis of virus-like particles. Biotechnol. Bioeng. 100:28-37.

14. Bundy, B.C. and J.R. Swartz. 2011. Efficient disulfide bond formation in virus-like particles. J. Biotechnol. 154:230-239.

15. Isaksson, L., J. Enberg, R. Neutze, B. Göran Karlsson, and A. Pedersen. 2012. Expression screening of membrane proteins with cell-free protein synthesis. Protein Expr. Purif. 82:218-225.

16. Hovijitra, N.T., J.J. Wuu, B. Peaker, and J.R. Swartz. 2009. Cell-free synthesis of functional aquaporin $\mathrm{Z}$ in synthetic liposomes. Biotechnol. Bioeng. 104:40-49.

17. Klammt, C., F. Lohr, B. Schafer, W. Haase, V. Dotsch, H. Ruterjans, C. Glaubitz, and F. Bernhard. 2004. High level cell-free expression and specific labeling of integral membrane proteins. Eur. J. Biochem. 271:568-580.

18. Bundy, B.C. and J.R. Swartz. 2010. Site-specific incorporation of p-propargyloxyphenylalanine in a cell-free environment for direct protein-protein click conjugation. Bioconjug. Chem. 21:255-263.

19. Muranaka, N., M. Miura, H. Taira, and T. Hohsaka. 2007. Incorporation of unnatural non- $\alpha$-amino acids into the $\mathrm{N}$ terminus of proteins in a cell-free translation system. Chembiochem 8:1650-1653.

20. Ozawa, K., K.V. Loscha, K.V. Kuppan, C.T. Loh, N.E. Dixon, and G. Otting. 2012. High-yield cell-free protein synthesis for site-specific incorporation of unnatural amino acids at two sites. Biochem. Biophys. Res. Commun. 418:652-656.

21. Patel, K.G. and J.R. Swartz. 2011. Surface functionalization of viruslike particles by direct conjugation using azide-alkyne click chemistry. Bioconjug. Chem. 22:376-387.

22. Woodrow, K.A. and J.R. Swartz. 2007. A sequential expression system for high-throughput functional genomic analysis. Proteomics 7:38703879 .

23. Hanes, J. and A. Plïckthun. 1997. In vitro selection and evolution of functional proteins by using ribosome display. Proc. Natl. Acad. Sci. USA 94:4937-4942.

24. Stapleton, J.A. and J.R. Swartz. 2010. Development of an in vitro compartmentalization screen for high-throughput directed evolution of [ $\mathrm{FeFe}]$ hydrogenases. PLoS One 5:e15275.

25. Fallah-Araghi, A., J.C. Baret, M. Ryckelynck, and A.D. Griffiths. 2012. A completely in vitro ultra high-throughput droplet-based microfluidic screening system for protein engineering and directed evolution. Lab Chip 12:882-891.

26. Beebe, E.T., S. Makino, A. Nozawa, Y. Matsubara, R.O. Frederick, J.G. Primm, M.A. Goren, and B.G. Fox. 2011. Robotic large-scale application of wheat cell-free translation to structural studies including membrane proteins. N Biotechnol 28:239-249.

27. Zubay, G. 1973. In vitro synthesis of protein in microbial systems. Annu. Rev. Genet. 7:267-287.

28. Anderson, C.W., J.W. Straus, and B.S. Dudock. 1983. Preparation of a cell-free protein-synthesizing system from wheat germ. Methods Enzymol. 101:635-644.

29. Spirin, A.S., V.I. Baranov, L.A. Ryabova, S.Y. Ovodov, and Y.B. Alakhov. 1988. A continuous cell-free translation system capable of producing polypeptides in high yield. Science 242:1162-1164.
30. Calhoun, K.A. and J.R. Swartz. 2005. An economical method for cell-free protein synthesis using glucose and nucleoside monophosphates. Biotechnol. Prog. 21:1146-1153.

31. Calhoun, K.A. and J.R. Swartz. 2005. Energizing cell-free protein synthesis with glucose metabolism. Biotechnol. Bioeng. 90:606-613.

32. Kim, T.W., J.W. Keum, I.S. Oh, C.Y. Choi, H.C. Kim, and D.M. Kim. 2007. An economical and highly productive cell-free protein synthesis system utilizing fructose-1,6-bisphosphate as an energy source. J. Biotechnol. 130:389-393.

33. Jewett, M.C. and J.R. Swartz. 2004. Mimicking the Escherichia coli cytoplasmic environment activates long-lived and efficient cell-free protein synthesis. Biotechnol. Bioeng. 86:19-26.

34. Jewett, M.C., K.A. Calhoun, A. Voloshin, J.J. Wuu, and J.R. Swartz. 2008. An integrated cell-free metabolic platform for protein production and synthetic biology. Mol. Syst. Biol. 4:220.

35. Jun, S.Y., S.H. Kang, and K.H. Lee. 2008. Continuous-exchange cell-free protein synthesis using PCR-generated DNA and an RNase E-deficient extract. BioTechniques 44:387-391.

36. Lesley, S.A., M.A. Brow, and R.R. Burgess. 1991. Use of in vitro protein synthesis from polymerase chain reaction-generated templates to study interaction of Escherichia coli transcription factors with core RNA polymerase and for epitope mapping of monoclonal antibodies. J. Biol. Chem. 266:2632-2638.

37. Carlson, E.D., R. Gan, C.E. Hodgman, and M.C. Jewett. 2011. Cell-free protein synthesis: applications come of age. Biotechnol. Adv. 30:1185-1194.

38. Ahn, J.H., H.S. Chu, T.W. Kim, I.S. Oh, C.Y. Choi, G.H. Hahn, C.G. Park, and D.M. Kim. 2005. Cell-free synthesis of recombinant proteins from PCR-amplified genes at a comparable productivity to that of plasmid-based reactions. Biochem. Biophys. Res. Commun. $338: 1346-1352$.

High Efficiency Gell Disrupter Mini BeadBeater-24

- Homogenizes 24 samples in $2 \mathrm{ml}$. vials.

- Proven more efficient horizontal vial shaking.

- High energy, variable speed motor. No motor cool-down time.

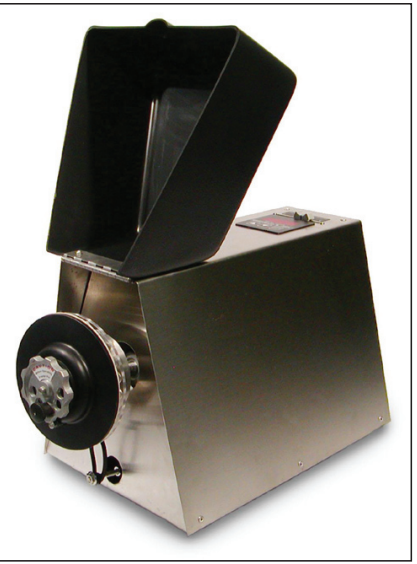

- Spores, bacterial yeast and tissue.

- Totally sealed system. No clean-up.

\section{5 BIOSPEQ PRODUCTS}

P.O. Box 788 - Bartlesville, OK 74005 Phone: 1-800-617-3363 • http://www.biospec.com 


\section{All labs are different...}
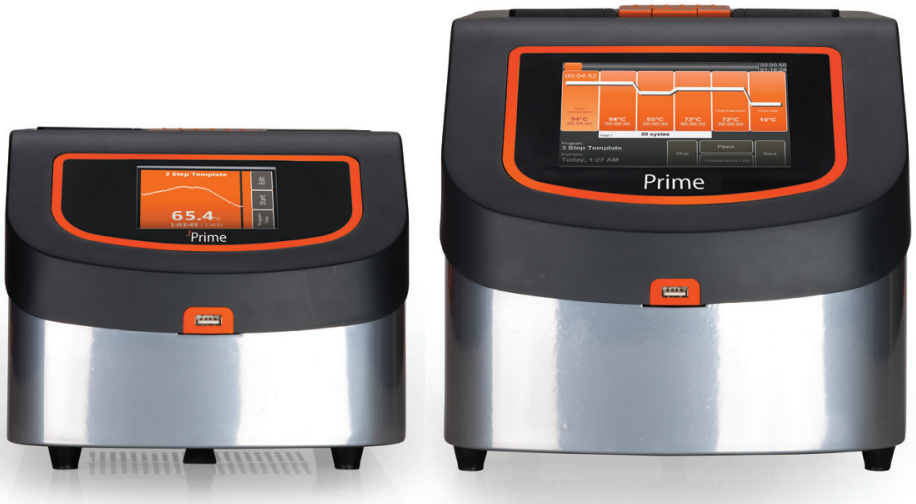

.... but your thermal cycling solution is the same
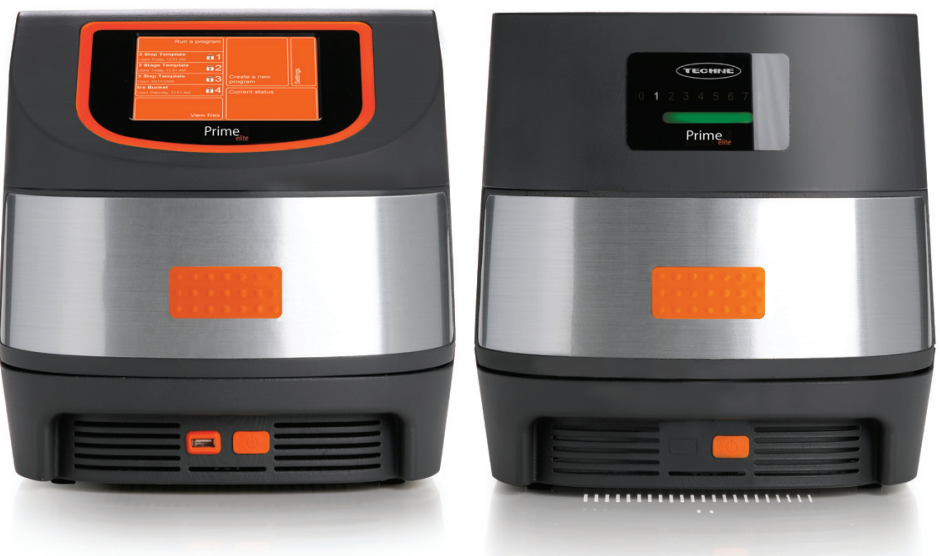

\section{New Techne ${ }^{\circledast}$ Prime Range}

- Grow from personal cycling to a 10 instrument network

- Experience the outstanding touch interface

- Upgrade to gradient capability only when required

- $\quad$ Be reassured by a 4 year warranty

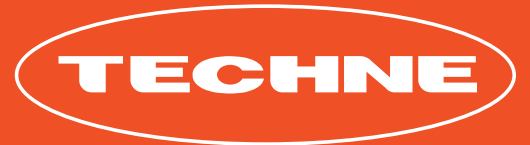

For a demo or further information contact

www.techne.com/enquiry.asp
39. Young, T.S., I. Ahmad, J.A. Yin, and P.G. Schultz. 2010. An enhanced system for unnatural amino acid mutagenesis in E. coli. J. Mol. Biol. 395:361-374.

40. Simpson, R.J. 2010. Large-scale extraction of recombinant proteins from bacteria. Cold Spring Harb. Protoc. 2010:pdb.prot5484.

41. Jiang, Y.-X., J.-G. Wu, K.-Q. Yu, C.-X. Ai, F. Zou, and H.-W. Zhou. 2011. Integrated lysis procedures reduce extraction biases of microbial DNA from mangrove sediment. J. Biosci. Bioeng. 111:153-157.

42. Johnson, B.H. and M.H. Hecht. 1994. Recombinant proteins can be isolated from $E$. coli cells by repeated cycles of freezing and thawing. Biotechnology (N Y) 12:1357-1360.

43. Harlow, E. and D. Lane. 2006. Immunoprecipitation: lysing bacteria by sonication. Cold Spring Harb. Protoc. 2006:pdb.prot 4532 .

44. Benov, L. and J. Al-Ibraheem. 2002. Disrupting Escherichia coli: a comparison of methods. J. Biochem. Mol. Biol. 35:428-431.

45. Breiling, A. and V. Orlando. 2006. Chromatin immunoprecipitation (ChIP) of protein complexes: mapping of genomic targets of nuclear proteins in cultured cells. Cold Spring Harb. Protoc. 2006:pdb. prot 4560.

46. Simpson, R.J. 2010. Small-scale extraction of recombinant proteins from bacteria. Cold Spring Harb. Protoc. 2010:pdb.prot5483.

47. Futai, M. 1974. Orientation of membrane vesicles from Escherichia coli prepared by different procedures. J. Membr. Biol. 15:15-28.

48. Ho, C.W., W.S. Tan, W.B. Yap, T.C. Ling, and B.T. Tey. 2008 Comparative evaluation of different cell disruption methods for the release of recombinant hepatitis B core antigen from Escherichia coli. Biotechnol. Bioprocess Eng. 13:577-583.

49. Hummel, W. and M.-R. Kula. 1989. Simple method for small-scale disruption of bacteria and yeasts. J. Microbiol. Methods 9:201-209.

50. Miller, D.N., J.E. Bryant, E.L. Madsen, and W.C. Ghiorse. 1999 Evaluation and optimization of DNA extraction and purification procedures for soil and sediment samples. Appl. Environ. Microbiol. 65:4715-4724.

51. Kim, D.M., T. Kigawa, C.Y. Choi, and S. Yokoyama. 1996. A highly efficient cell-free protein synthesis system from Escherichia coli. Eur. J. Biochem. 239:881-886.

52. Zheng, H., J. Yin, Z. Gao, H. Huang, X. Ji, and C. Dou. 2011. Disruption of Chlorella vulgaris cells for the release of biodieselproducing lipids: a comparison of grinding, ultrasonication, bead milling, enzymatic lysis, and microwaves. Appl. Biochem. Biotechnol. 164:1215-1224.

53. Doulah, M.S. 1977. Mechanism of disintegration of biological cells in ultrasonic cavitation. Biotechnol. Bioeng. 19:649-660.

Received 5 July 2012; accepted 7 August 2012.

Address correspondence to Bradley C. Bundy, Department of Chemical Engineering, Brigham Young University, 350S Clyde Building, Provo, UT, USA. Email: bundy@byu.edu

To purchase reprints of this article,contact: biotechniques@fosterprinting.com 